\title{
Management of Resorbed Mandibular Ridge with Neutral Zone Technique: A Case Report
}

\author{
Sharma $\mathrm{R}^{1 *}$, Mathema $\mathrm{S}^{2}$, Pathak $\mathrm{B}^{3}$ \\ ${ }^{1}$ Lecturer, Department of Prosthodontics, Nepal Medical College, Kathmandu, Nepal \\ ${ }^{2}$ Professor, Department of Prosthodontics, People's Dental College and Hospital, Kathmandu, Nepal \\ ${ }^{3}$ Assistant Professor, Department of Prosthodontics, People's Dental College and Hospital, Kathmandu, Nepal
}

\begin{abstract}
Patients with resorbed mandibular ridge posses a challenge for prosthodontic rehabilitation. The ongoing diminution of denture foundation defies the basic mechanism of denture stability and support. The technique of neutral zone to construct a denture that is shaped by muscle function and is in harmony with the surrounding oral structures can remarkably improve prognosis of such patients. The neutral zone is the area in the oral cavity where during function; the forces of the cheeks and lips pressing inward neutralize the forces of the tongue pressing outward. Thus physiologically optimal teeth arrangement and harmonious denture contours and can be achieved to maximize prosthesis stability, comfort, and function for patients.

This clinical report describes rehabilitation of a patient with severely resorbed mandibular ridge using neutral zone impression technique.
\end{abstract}

Key words: neutral zone, resorbed mandibular ridge, denture stability

\section{Introduction}

$\mathrm{T}$

The 'neutral zone' has been identified as a potential denture space where forces imposed by tongue directed outward are neutralized by inwardly directed forces originating from cheeks and lips ${ }^{1}$. These neuromuscular forces vary in magnitude and direction in different areas of the oral cavity, different individuals and periods of life ${ }^{2}$.

Loss of teeth leading to changes like ridge resorption, tongue expansion and muscle laxity of face; makes individual teeth positioning challenging ${ }^{3}$. Complete dentures serving as aesthetic and functional substitutes of structures inside oral cavity should be able to function synergistically with all surrounding

\footnotetext{
*Corresponding Author

Dr. Rinu Sharma, Lecturer, Department of Prosthodontics, Nepal Medical College, Kathmandu, Nepal.

E-mail:dr.sharmarinu@gmail.com
}

musculature ${ }^{4}$. Failing to recognize the harmony of neuromuscular function in tooth positioning and flange contour often results in dentures that are unstable and unsatisfactory.

The neutral zone technique is a suitable approach for these situations but is one that is valuable and yet not often practiced.

\section{Clinical Case Report}

A 72-year-old lady reported to Department of Prosthodontics, Peoples Dental College and Hospital with chief complaint of unsatisfactory mandibular denture. She was unable to wear mandibular denture due to lack of retention and stability and presented to us with only maxillary denture, which also appeared esthetically unsatisfactory. (Fig.1)

Intra oral examination revealed maxillary arch with flabby tissue on anterior region (Fig.2) and resorbed mandibular denture foundation (Fig.3). Maxillary complete denture with relief 
on flabby tissue area and mandibular complete denture with neutral zone technique was planned for this patient.

\section{Procedure}

Primary impressions were made in stock metal trays and casts poured in Type II dental plaster. Wax spacer was placed on both maxillary and mandibular arch with double spacer on maxillary anterior area. Relief vents were placed on maxillary flabby tissue area and final impression was made with zinc oxide eugenol impression paste (Fig. $4 \& 5$ ) The record bases with wax occlusion rims were fabricated to record tentative Occlusal Vertical Dimension (OVD) and face bow transfer was done (Fig. 6). Centric relation record was made and casts were mounted onto semi adjustable articulator.

On lower cast another temporary record base was fabricated with orthodontic wire bent and attached to it (Fig. 7). This helped in the retention of molding compound material. The mix of impression compound and greenstick compound in the ratio of 3:7 was softened in water bath, kneaded and shaped over the record base and was placed into patient's mouth.

The patient was then asked to perform different physiological and functional movements like swallowing, sucking, pursing lips, sipping water, protruding tongue, pronouncing vowels and speaking. During these movements the forces from muscles of lips, cheeks, and the tongue, molded the material into a definite shape and space. This recorded the neutral zone space (Fig. 8).

The excess material was cut and was molded until OVD was maintained on articulator. (Fig. 9) After complete molding of the material it was placed in cool water bath to set.

The neutral zone impression so obtained was placed back on master cast, location grooves were cut on the cast and it was covered with dental plaster index around the impression on both the labial and lingual sides (Fig. 10).

The compound occlusion rim was now removed and the plaster index preserved the neutral zone space. This space was filled with modeling wax for teeth arrangement to be done. The positioning of teeth during arrangement was verified time and again by placing the index together (Fig. 11).

Once the waxed up dentures were ready, they were checked in the patient's mouth for esthetics, phonetics and occlusion (Fig. 12).

After the trial dentures were deemed satisfactory, the dentures were finished, polished and inserted into the patient's mouth (Fig.13). Thus fabricated dentures were esthetic, retentive as well as stable. The patient was comfortable as well as satisfied with the new dentures (Fig. 14).

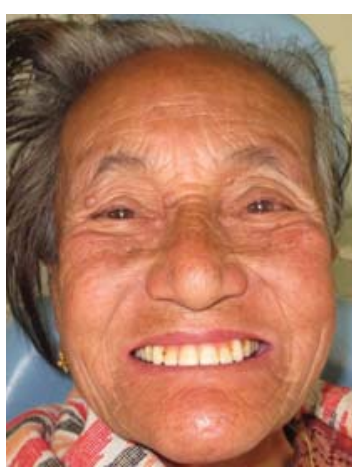

Figure 1: Patient with previous denture

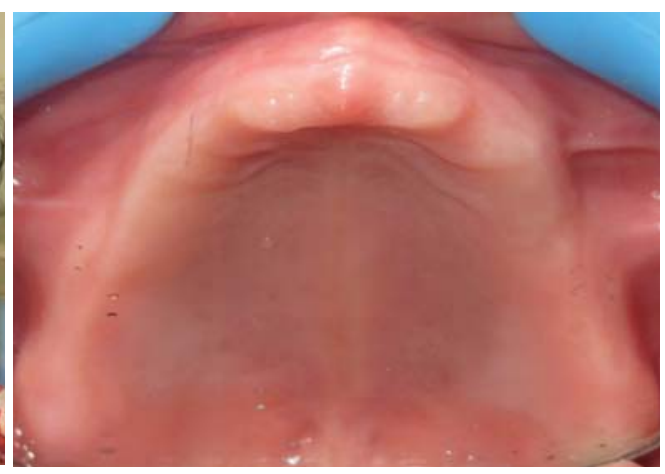

Figure 2: Maxillary edentulous arch

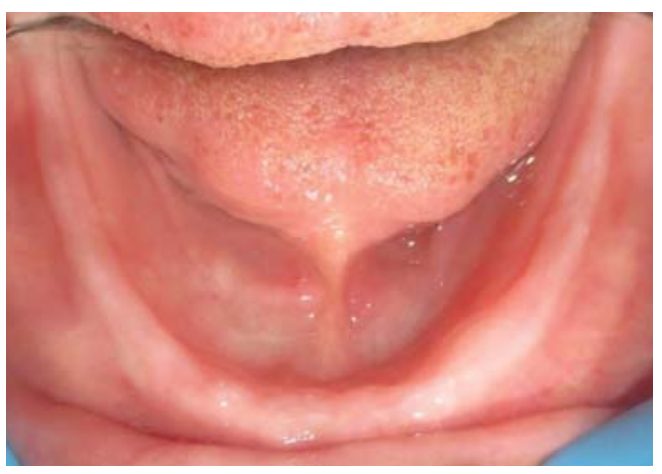

Figure 3: Mandibular edentulous arch 


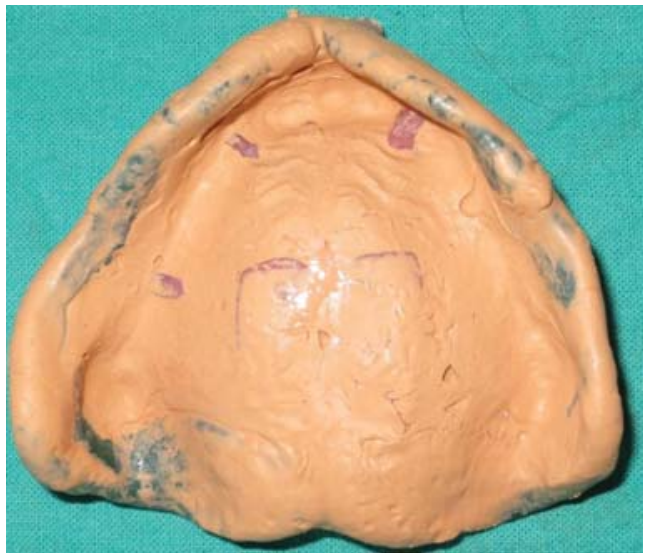

Figure 4: Maxillary final impression

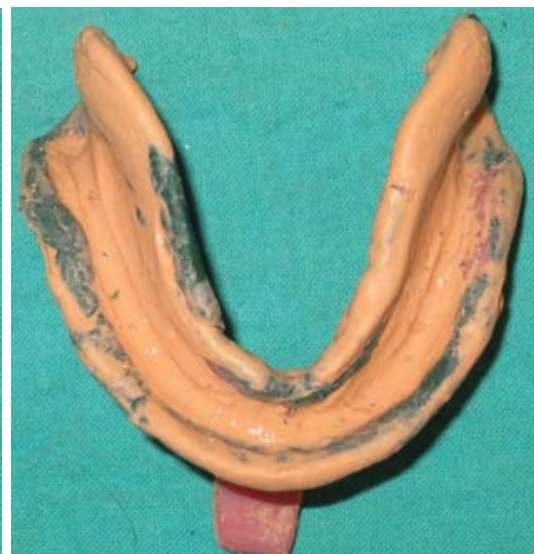

Figure 5: Mandibular final impression

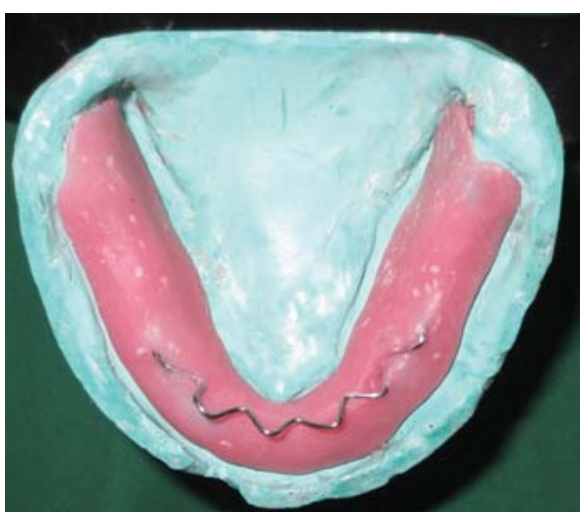

Figure 7: Temporary denture base with metal wire

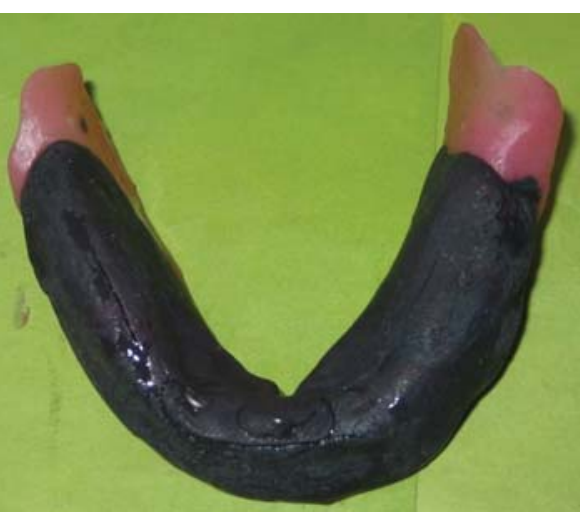

Figure 8: Impression molded in neutral zone

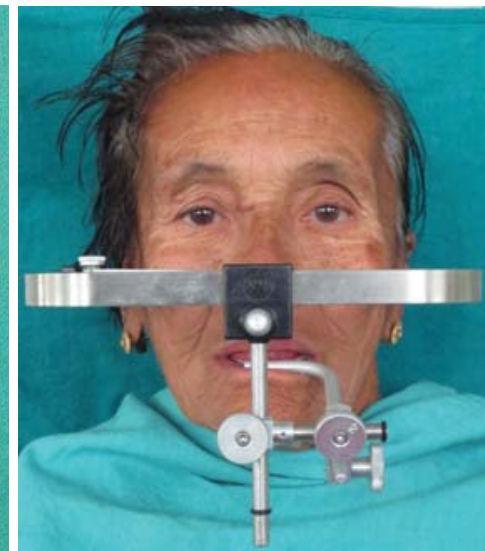

Figure 6: Face bow record

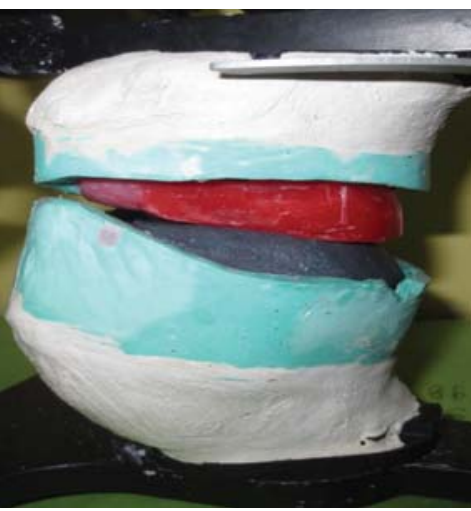

Figure 9: Molded occlusion rim verifying $O V D$

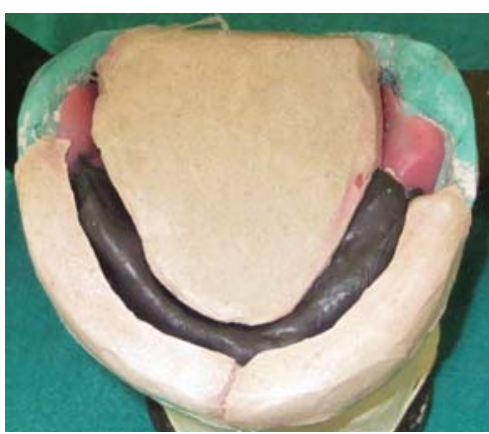

Figure 10: Dental Plaster index to preserve neutral zone

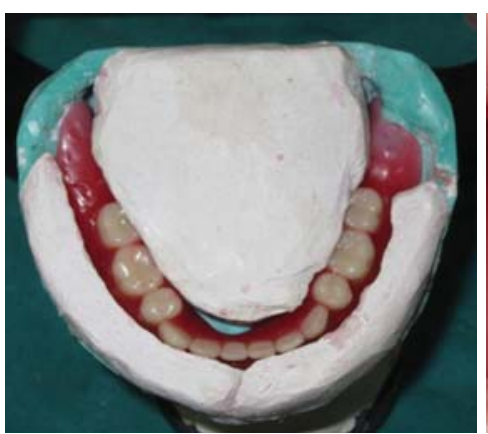

Figure 11: Dental Plaster index used to verify teeth positioning

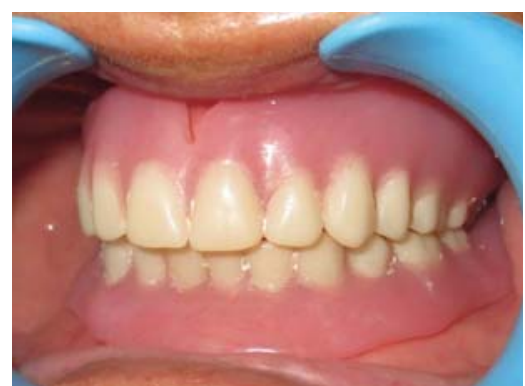

Figure 13: Denture Insertion

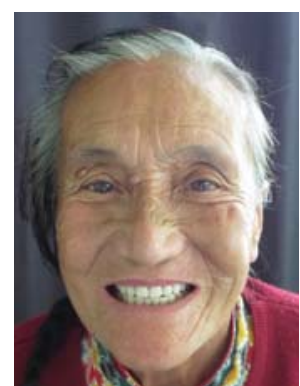

Figure 14: Patient with her new dentures 


\section{Discussion}

Neutral zone is that area or position where the forces between the tongue and cheeks or lips are equal ${ }^{1}$. With increasing alveolar ridge resorption, the denture base area becomes smaller and posses less role in denture retention and stability ${ }^{5}$. The aim of neutral zone technique is to position teeth as well as denture flanges in the potential zone of equilibrium where in forces acted upon it is very minimal.

The neutral zone technique has been widely described by various authors with different synonyms like zone of minimal conflict ${ }^{6}$, zone of equilibrium ${ }^{7}$, zone of least interference ${ }^{8}$, denture space $^{9}$, and potential denture space ${ }^{10}$.

As Sir Wilfred Fish has explained, per square unit of the polished surface can be as large as or larger than impression and occlusal surfaces combined, depending on anatomic structure of an individual ${ }^{11}$. So, the importance of 'polished denture contours' in denture stability and function cannot be over ruled.

A number of literatures have attempted to provide technique of molding of the neutral zone space $^{6-10}$. Kursoglu ${ }^{12}$ recommended tissue conditioners for the same. Since tissue conditioners do not have body, it is difficult to use even after supporting it with wire loops. Impression plaster advocated by Johnson ${ }^{13}$ is messy and cumbersome to use and also there is risk of swallowing fractured fragments of plaster during molding.

We have utilized the mix of impression and green stick compound, which will provide adequate molding of the material as well as be stable and self-supportive once it sets. Beresin and Schiesser ${ }^{4}$ and Cagna et $a l^{14}$ have also utilized modeling plastic for recording neutral zone. The use of a soft, moldable material being placed into the mouth with patients performing different functions is to capture in greater detail the actions of the lips, cheeks and tongue. These actions determine the tooth position as well as shape the polished surfaces of denture. The muscular forces generated will then aid in the retention and stabilization of the denture rather than dislodging it during function ${ }^{3}$.

In a clinical study, Fahmy and $\mathrm{Kharat}^{15}$, evaluated patient's satisfaction for complete dentures made with either a conventional or a neutral zone technique. Subjects reported greater comfort and improved speech clarity with the dentures fabricated using the neutral zone technique compared with their conventional prepared ones.

The other advantages with this technique are reduced food lodgment, good esthetics due to facial support and proper positioning of the posterior teeth, which allows sufficient tongue space $^{16}$.

\section{Conclusion}

Neutral zone impression technique can be utilized for fabricating dentures that are in harmony with surrounding muscular forces. This simple impression technique for artificial teeth positioning and contouring of polished surfaces can be of great significance in achieving highly stable and functional dentures, which will lead to increased patient satisfaction and improvise treatment outcome in compromised denture bearing foundation.

\section{References}

1. The glossary of prosthodontic terms. J Prosthet Dent 2005;94:10-92

2. Beresin VE, Schiesser FJ, editors. Neutral zone in complete and partial dentures. $2^{\text {nd }}$ ed. St. Louis: Mosby; 1979.p. 73-108.

3. Fahmi FM. The position of the neutral zone in relation to the alveolar ridge. J Prosthet Dent 1992; 67:805-9

4. Beresin VE and Schiesser FJ. The neutral zone in complete dentures.J Prosthet Dent 2006; 95:93-101

5. Atwood D A. Post extraction changes in the adult mandible as illustrated by micrographs of midsagital sections and serial cephalometric 
roentgenograms. J Prosthet Dent 1963; 13:810824.

6. Matthews E. The polished surfaces. Br Dent J 1961;111:407-11.

7. Grant AA, Johnson W. An introduction to removable denture prosthetics. $1^{\text {st }}$ ed. Edinburgh: Churchill Livingstone; 1983. p. 24-8.

8. Wright SM. The polished surface contour: a new approach. Int J Prosthodont 1991;4:159- 63.

9. Schlosser RO. Complete denture prosthesis. $1^{\text {st }}$ ed. Philadelphia: WB Saunders; 1939. p. 18390.

10. Roberts AL. The effects of outline and form upon denture stability and retention. Dent Clin North Am 1960;4:293-303.

11. Fish E W. An analysis of the stabilizing factors in full denture construction. Br Dent J1931; 52:559-570.
12. Kursoglu P, Ari N, Calikkocaoglu S. Using tissue conditioner material in neutral zone technique. NY State Dent J. 2007;73:40-2.

13. Johnson A, Northeast SE. The unstable lower full denture-a practical and simple solution. Restor Dent. 1989;5:82-90

14. Cagna DR, Massad JJ, Schiesser FJ. The neutral zone revisited: from historical concepts to modern application. J Prosthet Dent 2009;10:405-12.

15. Fahmy FM, Kharat DU. A study of the importance of the neutral zone in complete dentures. J Prosthet Dent1990;64:459-62.

16. Lott F, Levin B. Flange technique: an anatomic and physiologic approach to increased retention, function, comfort and appearance of dentures. J Prosthet Dent1966;16:394-413. 